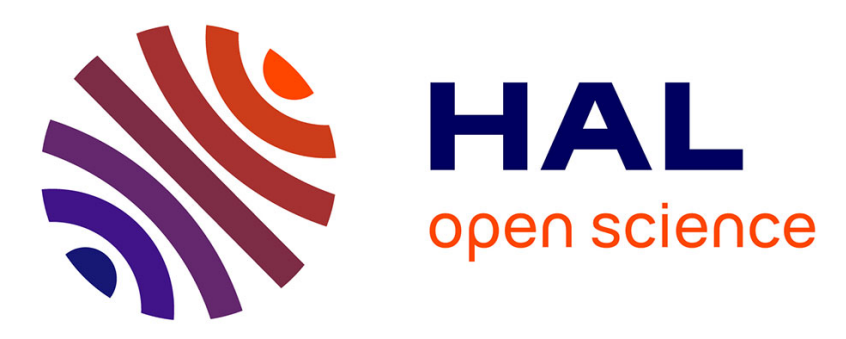

\title{
Errata Commande automatique du système d'orientation des héliostats d'une centrale solaire à tour
}

\author{
A.M. Malykoff, R.R. Aparissi
}

\section{To cite this version:}

A.M. Malykoff, R.R. Aparissi. Errata Commande automatique du système d'orientation des héliostats d'une centrale solaire à tour. Revue de Physique Appliquée, 1980, 15 (7), pp.1278-1278. 10.1051/rphysap:019800015070127800 . jpa-00244851

\section{HAL Id: jpa-00244851 https://hal.science/jpa-00244851}

Submitted on 1 Jan 1980

HAL is a multi-disciplinary open access archive for the deposit and dissemination of scientific research documents, whether they are published or not. The documents may come from teaching and research institutions in France or abroad, or from public or private research centers.
L'archive ouverte pluridisciplinaire HAL, est destinée au dépôt et à la diffusion de documents scientifiques de niveau recherche, publiés ou non, émanant des établissements d'enseignement et de recherche français ou étrangers, des laboratoires publics ou privés. 


\section{Errata}

\section{Commande automatique du système d'orientation des héliostats d'une centrale solaire à tour}

A. M. Malykoff et R. R. Aparissi

Revue Phys. Appl. 15 (1980) 377-382.

A la page 377 lire :

$$
\begin{aligned}
& \operatorname{tg} \beta=\frac{-\sin \alpha_{\mathrm{i}} \cos \theta+\sin a \cos h}{-\cos \alpha_{\mathrm{i}} \cos \theta+\cos a \cos h}, \\
& \operatorname{tg} z=\cos \beta \frac{\sin \theta+\sin h}{-\cos \alpha_{\mathrm{i}} \cos \theta+\cos a \cos h},
\end{aligned}
$$

où

$\sin h=\sin \varphi \sin \delta+\cos \varphi \cos \delta \cos K t$, $\sin a \cdot \cos h=\cos \delta \sin K t$, $\cos a \cdot \cos h=-\cos \varphi \sin \delta+\sin \varphi \cos \delta \cos K t$, $\sin \theta=\frac{\Delta H}{\sqrt{R_{\mathrm{i}}^{2}+(\Delta H)^{2}}} ; \quad \cos \theta=\frac{R_{\mathrm{i}}}{\sqrt{R_{\mathrm{i}}^{2}+(\Delta H)^{2}}}$. 